\title{
LIMITACIONES ECONOMICAS DEL CAMPESINADO ALICANTINO Y SU RECURSO AL CREDITO PRIVADO DURANTE EL SIGLO XIX
}

\author{
VICENTE CONEJERO MARTÍNEZ
}

Universidad de Alicante

\section{LAS LIMITACIONES ECONOMICAS DEL CAMPESINADO ALICANTINO Y SU RECURSO AL CREDITO PRIVADO DURANTE EL SIGLO XIX}

La mayor parte de la población activa española del siglo pasado vivía en las zonas rurales y trabajaba en el campo, sin que pueda olvidarse el auge extraordinario que el sector industrial alcanzó, especialmente, a partir de la segunda mitad del siglo, con el despegue de la Revolución Industrial. Esta industrialización, en el caso español, estuvo muy condicionada geográficamente, ya que tan sólo se localizaba en determinados puntos de la periferia.

La gran masa de trabajadores continuaba siendo absorbida por el sector primario, es decir, por la agricultura y a pesar de las transformaciones que se llevaron a cabo durante esta centuria referentes al trasvase de la propiedad de las "manos muertas" a propiedad privada, por las desamortizaciones, y a la desvinculación de las tierras de los mayorazgos, la Agricultura avanzó muy lentamente, durante todo el siglo, predominando un tipo de explotación agrícola tradicional, caracterizado por una tendencia a producir para tener un poco de todo y no tener que comprar, se producía lo que se necesitaba para consumir, y se consumía lo que se producía.

En el fondo de la cuestión, subsistía una precariedad monetaria en el agricultor; el campesino tradicional casi siempre an- 
duvo mal de dinero y por ello prefería pagar en especie los impuestos, derechos señoriales y arrendamientos de la tierra y no en metálico.

De este modo, para evitar dispendios en la compra de artículos alimentarios, tanto para sí como para el resto de la familia, el campesino procuraba practicar un autoconsumo, basado en la diversidad productiva (policultivo). Así, en su casa, no solian faltar los cereales, el aceite, vino, legumbres, frutas...

Junto a la producción agraria indispénsable para la alimentación de la familia, contaba con un complemento importante, cual era la cría de animales domésticos: aves de corral, conejos, cabras, ovejas, alguna vaca y los animales de tiro necesarios para las tareas del trabajo del campo.

Este policulivo destinado primordialmente al autoconsumo y la subsistencia, no descartaba totalmente la necesidad de acudir a los mercados locales y comarcales, en algunas ocasiones para abastecerse de aquellas cosas que escapaban de las posibilidades productivas de la pequeña empresa agraria. Cabe citar, por ejemplo, los vestidos de mejor calidad y confección que compraban para las grandes ocasiones, como fiestas, bodas, entierros...; la compra de animales de tiro para el trabajo y acarreo... y las pertinentes a la provisión de aperos y demás utiIlaje agrícola.

Dentro de este marco de una agricultura tradicional, con unos procedimientos técnicos en cuanto al cultivo de la tierra, muchas veces anticuados y poco eficaces, con rendimentos bajos; con escasos excedentes comercializables, las condiciones de la vida material de campesinado alicantino del siglo XIX, fueron, por lo general, muy duras, llegando con bastante frecuencia a situarse en niveles de verdadera miseria.

De los muchos aspectos que podrían ser tratados, al intentar analizar las condiciones materiales de la vida del campesinado decimonónico, estas páginas se centran en uno que, induda. blemente, contribuía a agravar la situación de penuria en que éste tenía que vivir. Se trata de la carga que para muchos suponía la práctica generalizada de préstamos por los que se cobraban intereses abusivos, es decir, de la necesidad que el campesino 
tenía de acudir al préstamo de dinero de los particulares más o menos adinerados, en un mercado de dinero nada transparente y en una época, en la que las instituciones bancarias se encontraban muy poco desarrolladas.

La necesidad de acudir a este sistema privado de crédito aumentaba las dificultades de unas economías, ya de por sí débiles.

Para la mayoría de pequeños campesinos, sus necesidades diarias de alimentación y vestido agotaban sus escasos recursos.

Si se trataba de braceros, la desproporción constante entre precios y salarios les colocaba en una situación de penuria muy cercana a la miseria.

Los pequeños propietarios con insuficiente tierra y los arrendatarios, ante la escasez de excedentes que comercializar y los bajos precios pagados al productor, caso de haber algún excedente, estaban condenados a caer irremediablemente en manos de los prestamistas y los usureros, al no existir una forma de crédito oficial para el campo.

En la huerta de Orihuela -escribe la Junta Agronómica de la Provincia de Alicante-, en su respuestas a la encuesta agraria de 1849:

Entran en lo común, los arrendadores a cultivar sus haciendas con un ganado caballar o vacuno, que si alguna vez basta para las operaciones de labranza y trilla, no es bastante considerable para proveer de estiércoles que escasean en aquel territorio.

Su capital en efectivo es sumamente limitado y se ven en la precisión de tomar fiadas las semillas y algunas veces, los granos y el aceite que necesitan para su sustento, asi como algunas cantidades de dinero para las escardas y los crecidos gastos que causa la cosecha del cáñamo, todo lo cual reintegran en las cosechas a sus prestamistas ${ }^{1}$.

En la misma encuesta que acabamos de mencionar, en el número 14 se pregunta:

1. Archivo General del Ministerio de Agricultura, Bancos Agrícolas, leg. 123, expte. 4-4 bis, años 1849-1856. 
Por lo general, los propietarios y colonos cultivadores de la provincia ¿necesitan dinero para atender sus esplotáciones (sic) agrícolas? ¿Lo buscan? ¿Cuando lo buscan lo encuentran a la medida de sus necesidades? ¿A qué interés lo logran y a qué plazo? ¿El colono que sobre sus productos o su firma quiere levantar dinero, lo encuentra? ¿A qué precio?.

Las contestaciones de las distintas Juntas Agronómicas provinciales, casi todas son unánimes en reconocer la descapitalización del campo, y la necesidad de acudir al crédito privado, teniendo que pagar el campesino unos intereses abusivos, al recibir dinero prestado.

Las contestaciones que da.la Junta de Agricultura de Alicante a tales interrogantes, es la siguiente:

Los propietarios y colonos, con cortisimas escepciones (sic) necesitan siempre dinero para la esplotación de sus tierras; pagan intereses usurarios por él, no siendo raro en las montañas el que tomen un cahíz de cebada para restituir el trigo. Se obligan, generalmente, a volver los préstamos a las cosechas, y si no pueden verificarlos, su ruina es inevitable, por los sobre intereses que se les ecsijen (sic). Los préstamos en dinero se hacen generalmente sobre la hipoteca de los frutos, y con las onerosisimas condiciones que se han manifestado ${ }^{2}$.

Como garantía del préstamo concedido, el prestamista no sólo exigía la hipoteca de la futura cosecha, sino que muchas veces, se hipotecaba una finca como aval de préstamo. Prueba de lo que venimos diciento lo podemos constatar en los Protocolos Notariales, en los que aparecen abundantes testimonios de tales hipotecas. Sirvan de ejemplo, el caso de Pascual Barrachina, labrador, vecino de Cocentaina quien en 1854 hipoteca una finca de "dos jornales de tierra viña y huerta, lindante con Tomás Giner, Vicenta García y Juan Montano, por la obligación de pagar a Mauro García y Espinós 960 Reales, dentro de un año" 2 bis.

Otro ejemplo, más gravoso todavía para el que se veía en la necesidad de pedir dinero prestado, lo tenemos cuando el prestamista obligaba al que recibía el dinero en préstamo, a que le hi-

2 Ibidem: respuesta a la pregunta número 14 de la encuesta agrícola.

2 bis Archivo Histórico Provincial de Alicante, Protocolos Notariales, Registro de la Propiedad: Lorcha, Balones, Benillup, C. H. pág. 45, fol. 4, años 1860-1862. 
ciese escritura de una finca, como si la comprara, y sólo podía recuperarla el deudor, en el caso de pagar la deuda, vendiéndosela de nuevo al prestamista. Así, en 1862, acuden ante el Notario de Cocentaina, José Espinós y Artola, labrador vecino de Balones y Vicente Segura y Nadal, también labrador y del mismo pueblo para escriturar la venta de una finca comprensiva como de "medio jornal de tierra secano, parte campa y parte plantada de viñas, lindante por Levante con tierras de Blai Puig, por Poniente con las del comprador y por el Norte y el Sur con las de Bautista Rodríguez... con el pacto y condición de si dentro el término de dos años, a contar desde el día de todos Santos próximo hasta el de 1864, vuelva al comprador Vicente Segura los $1.650 \mathrm{Rls}$, le ha de retornar y rotrovender la deslindada tierra y no verificándolo dentro de dicho plazo, quedará del absoluto dominio del mismo" 2 ter.

En Cataluña, los propietarios y colonos se veían en la necesidad de pedir dinero prestado para el sementero y otras necesidades diarias, "teniendo que pagar un rédito anual oscilante entre el 6 y el $25 \%$.

En Castilla ocurría otro tanto. Así la Junta de Agricultura de Toledo, escribe a este respecto:

Los propietarios y colonos cultivadores necesitan generalmente dinero para atender a sus esplotaciones agrícolas. Lo buscan con ansia, pero desgraciadamente solo lo encuentran a un 30,50 o $70 \%$; a plazos cortos generalmente, hipotecando fincas, o la cosecha, o uno y otro a la vez, que es la causa de la decadencia y del descrédito actuales ${ }^{3}$.

En el campo andaluz, los colonos encontraban dinero para mejorar sus explotaciones, al $20 \%$, pero "siempre que el labrador hipoteque una finca a satisfacción del prestamistan.

Sobre los productos no se hacían préstamos. Era costum. bre generalizada el que el campesino pobre acudiera al préstamo para cubrir necesidades urgentes, entre las que cabe destacar:

2 ter. Ibídem: Protocolos Notariales, C. H. 6, fol. 211.

${ }^{3}$ Archivo General del Ministerio de Agricultura, Bancos Agrícolas, respuesta a la pregunta número 15 de la encuesta agrícola de 1849-1856. 
- Fl pago de la contribución.

- El impuesiu uこhro ranadería, pastos...

- Para cubrir necesidades de aiimentiación y vestido ante una mala cosecha, o ante una calamidad pública o privada. siembra.

- Para conseguir las semillas con que poder hacer la

No solía ser muy frecuente el que el campesino acudiera al prestamista o al usurero con el fin de obtener dinero con el que mejorar sus cultivos, con las inversiones pertinentes.

Según se desprende de las Encuestas Agrícolas realizadas a lo largo del siglo XIX, por el Ministerio de Fomento (las de 1849-56, la de 1883 y la de 1887) los préstamos en especie eran conseguidos por el agricultor a un precio mucho más elevado que los préstamos en metálico.

El precio del dinero prestado se encarecía mucho más si se trataba de grandes cantidades, si el préstamos se concedía por más tiempo que el acostumbrado, o si se preveía que el riesgo que tenía que afrontar el dinero prestado era mayor.

El interés que se cobraba por los préstamos en especie, sobrepasaba, por lo general, el $50 \%$.

En la provincia de Alicante, en las últimas décadas del siglo XIX, se hacian préstamos "de granos y frutos" por breves plazos, con un beneficio, a todas luces abusivo, del 50 ó 60 por cien.

En el Reino de Valencia, concretamente en Ayora, a finales del siglo XVIII y comienzos del XIX, el Señor territorial, Duque del Infantado realizaba préstamos en especie (cereales) a los labradores pobres. Dichos préstamos se hacían ante Notario y dos testigos. Los cereales prestados eran: trigo, cebada, centeno y avena.

Algo que siempre se consignaba en los documentos suscritos era el precio de los cereales, en el momento de hacer el préstamo, ya que será el punto de referencia, para la posterior devolución en dinero efectivo y donde se encierra el interés, que no 
aparece manifiesto en ningún caso, dado que se pagaba con la variación estacional ${ }^{4}$.

El interés que había que pagar por los préstamos en dinero era elevado y variaba mucho según las regiones y los casos concretos. Así, sabemos por el Informe de la Cámara de Comercio de Alicante que, en 1887, se cobraba, en algunos casos, hasta el 100 por 100 anual de interés y que los préstamos se hacian sobre hipoteca, cuando se trataba de numerario y por documentos privados, cuando se trataba de frutos a devolver en especie ${ }^{5}$.

El recurso al crédito se hacía siempre pensando en la próxima cosecha, pero, los beneficios netos que obtenía el campesino de la tierra que trabajaba eran muy pequeños, en los años en que la climatología no le era adversa. Los beneficios estaban en relación con los gastos de cultivo y con los rendimientos. En cuanto a los costes por hectárea de trigo, en el último tercio del siglo XIX, pueden cifrarse, poco más o menos, con arreglo al siguiente cuadro:

GASTOS POR HECTAREA SEMBRADA DE TRIGO (En pesetas)

Tres labores de barbecho a 10 ptas........ . . 30

Dos labores de sementera a 5 ptas......... $\quad 10$

Dos hectolitros de semilla a 20 ptas....... $\quad 40$

Dos labores de escarda:

6 mujeres, 2 dias, a 1 pta.................. 24

Abono proporcional ............................... $\quad 80$

Siega, trilla, limpia.................................. $\quad 40$

Renta de la tierra ................................... $\quad 25$

Riegos.................................................... $\quad 15$

Gastos generales

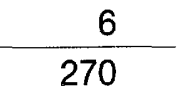

Total

FUENTE: Crisis Agricola y pecuaria, Tomo IV, pág. 286

4 Gimeno Sanfeliú, María Jesús, "Datos para el estudio del endeudamiento del campesinado de Ayora (1786-1805)", en Estudis, núm. 9, 1981-82, Fac. de Geografía e Historia, Depto. de Historia Moderna, Valencia.

5 "Crisis agrícola y pecuaria", tomo II, pág. 105, Contestación de la Cámara de Comercio de Alicante (1887). 
En la tierras de secano, los gastos de cultivo eran menores ya que las labores y el abono que se empleaba eran más reducidos.

Los rendimientos, por lo general, eran bajos, pudiéndose calcular en un 1,5 al $2 \%$ el interés que, en años regulares, obtenía el labrador de su propiedad y capital de explotación.

En cuanto a la producción media de trigo por unidad sembrada, puede cifrarse en 10 hectolitros por hectárea, en un año normal. Como puede observarse, los rendimientos no dejaban mucho margen de ganancia al agricultor; de àhí la necesidad de procurarse dinero, acudiendo al préstamo.

Las malas cosechas que provocaban crisis de subsistencia, las desgracias familiares junto con las elevadas y duras exigencias de un régimen señorial muy extendido en la región valenciana, serán las causas principales del endeudamiento del campesino y su necesidad agobiante de recurrir al crédito.

En el País Valenciano, según Manuel Ardit, se pagaba generalmente «un cahíz de trigo por cada cien libras del valor de la hacienda; pero, mientras el valor de ésta se mantuvo inalterado, los precios de los granos experimentaron un aumento constante" ${ }^{6}$. De este modo, acosado por la necesidad el labrador buscaba al prestamista de la propia localidad para salir de apuros urodeándose la operación efectuada del misterio que ambos tenían interés en conservar".

Lo que ocurría no pocas veces, era el efecto contrario, es decir, que, en lugar de salir de apuros el campesino, se veía sumido en su propia ruina, al perder la escasa tierra que poseía y que se vio obligado a hipotecar para conseguir el préstamo solicitado. Una mala cosecha, por pedrisco o por heladas, era suficiente para empobrecer al agricultor por muchos años.

La no existencia del Crédito Agrícola oficial hasta primeros del siglo XX, obligaba a todos los campesinos necesitados de dinero, a acudir a los particulares que se aprovechaban al máximo de la necesidad ajena y de los apuros del que a ellos acudía, aña-

${ }^{6}$ ARdit LUCAS, Manuel, Revolución liberal y revuelta campesina, pág. 35. 
diendo una nota más de desazón y angustia a la débil economía doméstica del agricultor.

\section{BANCOS AGRICOLAS Y MERCADO DE CAPITALES}

El problema de la escasez de capitales en el medio rural, no era nuevo en el siglo XIX. También en los siglos anteriores el campesino tuvo necesidad de dinero y ante la no existencia del crédito público y oficial, se veía forzado a recurrir al crédito privado.

Para ayudar a los campesinos pobres, se crearon, a finales de la Reconquista, los llamados Pósitos, instituciones destinadas a almacenar granos y prestarlos a los vecinos necesitados, en condiciones muy favorables, sobre todo, en épocas de malas cosechas y escasez.

Además de remediar la falta de subsistencias en los pueblos, los Pósitos tenían otros cometidos como eran:

suministrar al labrador, en caso necesario, el grano y aun el metálico suficientes para promover las cosechas, nivelar, en lo posible, la desigualdad de éstas, acrecentar el cultivo, fomentar la abundancia de granos y combatir la escasez ${ }^{7}$.

La primera legislación sobre los Pósitos data de tiempos de Felipe II (1584).

La mayor importancia económica de esta institución, se alcanza en el siglo XVIII. En el siglo de la llustración, los Pósitos cumplieron una función económico-social muy significativa, ya que efectuaban operaciones de préstamo al agricultor para que pudiera sembrar, con un interés módico del $4,1 \%$.

Estos préstamos a los campesinos no se concedian tan sólo para la siembra, sino también para otros muchos casos de necesidad. Al mismo tiempo, los Pósitos fueron centros de planificación agraria e invertían sus beneficios en actividades de interés público.

7 Martinez Alcubilla, Marcelino, Diccionario de la Administración Española, 5. ${ }^{a}$ edición, tomo VII, pág. 779-780. 
En el siglo XVIII dependían del Consejo de Castilla y en el XIX, de la Secretaría de Hacienda. En 1906, se convierten en Bancos Agrícolas, dependiendo del Ministerio de Fomento. En 1931, formaron parte de las competencias del Ministerio de Agricultura, Industria y Comercio; y finalmente, en 1938, pasan al Ministerio de Agricultura, dentro del Servicio Nacional de Crédito Agrícola.

En cuanto a la creación de los Bancos Agrícolas, el proceso fue muy lento y zigzagueante a lo largo del siglo XIX.

Ya en 1841, un Decreto de la Regente autorizaba a los Jefes Políticos de cada provincia para que promoviesen la creación de Bancos Rurales o de Socorro "para el fomento de la Agricultura y la Ganadería".

En diciembre de 1883, un Real Decreto establecía una Comisión para que indagase hasta qué punto satisfacían las exigencias del crédito agrícola, los antiguos Pósitos.

Finalmente, el Código de Comercio promulgado el 22 de agosto de 1885, declaraba libre la creación de Bancos Agrícolas.

Los primeros Bancos Rurales, hasta que el Gobierno diese las leyes oportunas, se rigieron por la legislación de los antiguos Pósitos. El capital o fondo de estos Bancos se formaría con el dinero de los Pósitos, con acciones de los particulares y de las corporaciones municipales.

Los Ayuntamientos quedaban autorizados para «la enajenación de los predios rústicos y urbanos propios de los Pósitos" e invertirlos en estos Bancos Rurales. El importe de cada acción podia ser de mil reales en las capitales de provincia y de cuatrocientos reales en los demás pueblos de ella.

Las Cortes de ese año habían elevado una propuesta para la transformación de los Pósitos en Bancos Agrícolas, propuesta que no se aprobó.

En octubre de 1889, el Gobierno dirigió un Interrogatorio para conocer el estado y situación de los Pósitos y ver la conveniencia de convertir en metálico todo el capital activo y bienes inmuebles de los Pósitos, "con el fin de dar el mayor desarrollo posible al Crédito Agrícola sobre la base de aquella institución". 
Una prueba clara del interés del Estado por el Crédito Agrícola, lo podemos constatar en que, en las múltiples encuestas sobre la Agricultura, nunca de deja de preguntar y pedir información sobre el crédito agrario y sobre la conveniencia de crear instituciones financieras (Bancos Agrícolas) al servicio del campo y del campesino ${ }^{8}$.

La mayoría de los campesinos, tanto los medianos y pequeños propietarios, como los arrendatarios, necesitaban dinero para hacer frente a los gastos de siembra, recolección, contribuciones... sin contar otras necesidades de índole familiar.

A este respecto, en la Memoria sobre la Agricultura de la Provincia de Alicante de 1875, se insiste:

Si se desea variar los cultivos, modificar la condición de los terrenos, convirtiendo en regadio los muchos y buenos que existen de secano, hacer grandes plantaciones, introducir toda clse de mejoras y procurar, en fin, que la Agricultura salga del estado de apatia que hoy la domina y se ponga a la altura de otros países menos favorecidos por la Providencia, preciso es emplear capitales y no pequeños. Para conseguir un fin de intereses tan vital, ningún medio más provechoso que la creación de un Banco Agrícola que preste a los labradores necesitados, mediante una segura fianza, las cantidades que reclamen, haciéndoles pagar un módico interés que se fijaría en su tiempo y que nunca excediese del $5 \%{ }^{9}$.

Para justificar la necesidad de la creación de este tipo de Bancos, el Ingeniero agrónomo que redacta la mencionada $\mathrm{Me}$ moria, insiste en la falta de dinero que tiene el campesino, en cómo se ve obligado a recurrir a la usura y «al gremio de prestamistas del que nunca falta en los pueblos algún representante y que, como un gran favor, adelantan el dinero necesario a tipos de interés que, rara vez, bajan del $20 \%$ \%.

Este interés era alto y, para aquellos tiempos, abusivo; en muchos casos, conllevaba la desaparición de la pequeña fortuna de una familia labradora, por no haber tenido buenas cosechas

8 Cfr. Ias Encuestas Agrícolas de 1849, 1852, 1856, 1857, 1885, 1886.

9 Archivo de la Excma. Diputación Provincial de Alicante, Sección Fomento, leg. 12, 53, E. 1875: Memoria sobre la Agricultura de la Provincia de Alicante formada según Orden del Consejo Superior de Agricultura, Industria y Comercio de 23 de julio del presente año (1875) por el Ingeniero Agrónomo D. Agustín Echavarría, pág. 4. 
en dos o tres años. La creación de Bancos Agrícolas - pensaban-, podia poner fin a estos males.

¿De dónde procedería el capital para formar estos Bancos?

A finales del siglo XIX, ya el tema del crédito agrícola ha madurado lo suficiente, como para plasmarse en realidad.

Según las encuestas realizadas, el capital se formaría: "con los fondos de propios que existan aún en poder de los pueblos, un pequeño recargo sobre la contribución y los auxilios que pudiera proporcionar el Gobierno, además de las suscripciones voluntarias que vendrían a aumentar la base fundamental".

Amén de atender a la demanda de capital por parte de los agricultores, estos Bancos serían también Bancos de Depósitos, que abonarían un módico interés "proporcionando grandes ventajas este sistema a los labradores que, en años de buenas cosechas, no saben donde colocar sus capitales, sin riesgon.

Siguiendo esta línea, el Cabildo Municipal de Cocentaina se reúne, en diciembre de 1861 , con objeto de analizar la posibilidad de participar en la creación de un Banco Agrícola provincial, cuyo capital tendría por base el $80 \%$ procedente de los Bienes de Propios. Este Banco Agrícola, juzgaban, sería sumamente beneficioso para los particulares, para el Municipio y para el Estado; así, lo expresaba el Cabildo de Cocentaina:

Al particular, facilitándole por un módico interés y a plazos las cantidades que necesita para ordenar el sostenimiento de su industria agrícola y librándole del exhorbitante interés con que el especulador particular le estrecha y esclaviza; a la municipalidad, mejorando sus rentas en productos y garantia, puesto que, centralizada la administración del producto de aquellos bienes, habrán de aumentarse necesariamente sus utilidades con la fuerza acumulada de un capital bien definido, con el saneamiento de las hiptecas que se exigían para la seguridad de los préstamos; y al Estado, aumentando la masa imponible de la riqueza con la facilidad que se abrirán a la explotación del puntual recaudación de los impuestos y abriendo ancho campo a la actividad de un crecido número de agentes que, sin recursos hoy desarrollados, encontrarán mañana horosa y productiva su expansión ${ }^{10}$.

10 Archivo Municipal de Cocentaina, Cabildos, año 1861. 
Al final, el Ayuntamiento de Cocentaina aprobó su participación en el proyectado Banco Agrícola Provincial, dedicando al mismo todo el producto que correspondía al patrimonio común "por los bienes, derechos y censos vendidos o redimidos hasta la fecha en virtud de las leyes vigentes de desamortización y de los que, en lo sucesivo, se vendan o rediman".

El paso de una agricultura tradicional a un sistema de explotación agraria de tipo capitalista, no fue, en España, uniforme ni sistemático, coexistiendo ambos tipos de explotación, la tradicional y la capitalista, hasta nuestros dias. No obstante, después de las desamortizaciones muchos de los compradores de fincas, quedaron sin capital suficiente para iniciar una explotación adecuada de las tierras compradas, y por ello, cada día, se fue haciendo más urgente la necesidad de extender al campo, a las zonas rurales, el crédito, pues una agricultura moderna y competitiva, exigía inversión de capitales.

El campo español pedía a gritos un mercado crediticio donde el dinero fuera fácil de conseguir, y no excesivamente gravoso, pero, desafortunadamente, ésto no fue posible en el siglo XIX. 